\title{
How to Improve the Ability of Verbal Communication between Doctor and Patient
}

\author{
Jinguo Wang \\ Department of Urology \\ The First Hospital of Jilin University \\ Changchun, China \\ wangjinguolily@163.com
}

\author{
Na Wang* (corresponding author) \\ Department of Anesthesiology \\ The First Hospital of Jilin University \\ Changchun, China \\ wangna080613@163.com
}

\begin{abstract}
To explore implementation of language standardization training on the doctor-patient dialogue and evaluate the effect by the methods of analyzing and summarizing the concrete implementation situation of language standardization training in some hospitals. Through the doctorpatient dialogue language standardization training health care workers in the work can use normative language. The patient satisfaction increased. Doctor-patient dialogue language is a standardized training for medical personnel to develop verbal exchanges competence and is also a long-term task.
\end{abstract}

Keywords-Doctor-patient relationship ; communication;

verbal ability

\section{INTRODUCTION}

With the reform of medical system, doctor-patient relationship with tension, many changes have taken place in the doctor-patient relationship, to patients and hospitals have caused great damage and loss, the thorough analysis in one of the main reasons for this situation is the lack of mutual trust and respect between doctor and patient. The doctor-patient relationship to eliminate tension, resolving contradictions, needs the joint efforts of both doctors and participate in the whole society, needs more doctors to improve doctor-patient communication skills. Good doctor-patient communication and communication, is to create a harmonious doctor-patient relationship, improve doctor-patient the basis of mutual trust and cooperation, also is "taking patients as the center" the best embodiment.

\section{COMmunicAtion BetweEn Doctor AND PATIENT}

Customer relationship management (customer relationship management, CRM), as a management phenomenon already exist, however, as a kind of mature management idea and management technology is applied to hospital management, is the rise in recent years [1]. American marketing association defines CRM simple as: to assist enterprises to establish good relationship with customers, make both of us benefit management mode type.

\section{A. Verbal communication skills are important.}

Doctor-patient verbal interaction is the main components in the process of medical treatment. In recent years, the doctorpatient interaction between is attracting more and more from the linguistic, psychology, and medical scholars attention. Although the doctor-patient verbal interaction has become a hot topic, but the related research is more fragmented, and lack of reliable theoretical support [2].

Through to the existing literature about doctor-patient verbal interaction behavior, with the help of the new development of positive psychology theory, and using the method of quantitative analysis, this thesis positive orientation words between the doctor-patient interaction and its influence on patient satisfaction has carried on the exploratory research, verified the author proposed the first part of the "medical value chain".

This positive orientation in the process of visits to the doctor's words, the number of patient satisfaction questionnaire scores, and the length of the specific time for the detailed analysis, which proves the positive orientation words between doctor-patient interaction and patient satisfaction between the intensity of positive correlation, and points out that doctors should take the initiative in the process of interrogation, to exert positive psychological intervention in patients with to satisfy patients' psychological needs [3]. In addition, the results of this article indirectly proves that the medical from biological. Medical model is biological, psychological, social necessity of paradigm shift. Calls for doctors attach importance to their verbal communication skills in the process of physician visits so as to improve the therapeutic potential of interrogation, and thus improve patient satisfaction and medical quality.

This paper reviews the existing studies of doctor-patient interaction, including current research on doctor-patient interaction of different research perspectives, different research methods and research purposes. Mainly introduces the support of the study psychology theory. Analysis of corpus collection and transfer, data process and method are introduced. Mainly includes the detailed analysis of the corpus and the positive orientation of relationship between doctor-patient interaction and patient satisfaction.

\section{B. Comparison with the training system in other countries}

Traditional medical education is in the service of the biomedical model, this model fundamentally disregard patient dignity as a person, just take the patient as sick organism, deviated from the essence of medical humanities. Under this model, medical education only pay attention to the training of 
professional skills of medical students, ignoring the medical students should have the dedication and the formation of benevolence, ultimately affect the harmonious doctor-patient relationship. Also great changes have taken place in medical model, a comprehensive physical, psychological and social factors impact on human health and disease medical view, this is the biological - psychology - social medical model, the model of medical education should adapt to this change. The mission of higher medical education is to adapt to the social development, cultivate noble moral character knowledgeable medical skills of physical and mental health of high quality modern medical talents, the good doctor-patient communication skills is indispensable to medical students to become a qualified doctor [4]. This requires doctors pay more attention to social factors, in addition to constantly update professional knowledge, and improve the quality of the interpersonal communication skills and professional ethics. Interpersonal communication is the foundation of medical treatment activity, is the basic clinical skills. Good doctorpatient communication between can achieve mutual respect, mutual trust and increase the cohesion between doctor and patient, improve work efficiency, and can successfully achieve expected goals. Basic qualities in all fields, including communication skills become an important indicator.

At present, many medical colleges and universities in our country's education mode is still only attention to the cultivation of medical skills, while ignoring the resident of doctor-patient communication skills training. Society for medical talent cultivation put forward higher request, asked the doctor to have strong ability of doctor-patient communication [5].

\section{How to improve verbal communication skills?}

Communicate with the patient and family harmony. Doctors' professional ethics quality is the medical professionalism. It is formed in the medical practice development and creation, mainly reflected in the maintenance of life, respect life, value, motivation, and improve the quality of life. In recent years, the medical professionalism is from the government, market and industry itself more and more powerful influence, under the globalization trend of strong, medicine of Chinese and western countries are faced with more and more of the same problems." '41 in the tide of market economy in our country, the nation's moral ideas and behaviors, great changes have taken place. Actual interest and the professional spirit fierce collision happened, cause the whole society including the medical staff of medical professional spirit is more and more indifference, clinical doctors lack of affection and respect to people, utility or disregard for life, attaches great importance to the technology to belittle humanistic moral problems have caused extensive concern of the whole society." three (ABIM) foundation, in 2002 the American college of council of the American college of physicians A U.S. physicians foundation and the European union for physicians (European Federation of Internal Medicine) to jointly study and released the "New Medical Professionalism: one thousand physicians Charter" (Medical Professionalism in the New Millennium: A Physician Charter).The charter to established the three basic principles of professional spirit and a series of professional responsibility clear [6]. With three basic principles for the principle of "give top priority to benefit in patients with", "patient autonomy principle" and the principle of "social justice" : a series of professional responsibility include a commitment to improve the professional level, honest with patients, patient confidentiality, and keep proper relationship, to improve the quality of medical service, promote the popularization of medical services and fair allocation of limited resources, the innovation of scientific knowledge, and ensure the reliability of knowledge, by controlling the conflicts of interest, to maintain the credit, bear the liability for this professional interior, etc., constitute the main content of the new era of medical professionalism.№ in November 32005, the ethics committee, chairman of China physicians association, and sent all the doctor "for the declaration of the doctors professional spirit of the new century a physician" initiative, asked the doctor carefully study the declaration of a physician, sets up the good professional spirit.360 - degree evaluation is also known as degree feedback evaluation or multi-source feedback evaluation. The traditional performance evaluation, mainly by the evaluators were superior to evaluate its. While the 360 degree feedback evaluation, by people who have close relationship with be evaluators should include the evaluators superiors, peers, subordinates, and clients, etc., anonymous evaluate the evaluators were respectively. They also evaluate their evaluators on their own.

It can be used to measure managers' behavior comprehensively, and through the multifaceted feedback evaluation to promote managers improve their behavior. Since the late 20th century, European and American countries began to application for examination and assessment of 360 degrees for a lot of problems in the field of medical education, such as: the effects of residency training, medical service quality evaluation up 1 state. A 360- degree feedback as a "mirror", the assessed can find self, self-adjustment. Compared with the traditional evaluation method is more accurate and reliable, higher credibility, the error is small, fully embodies the 360 degree evaluation method for the development of individual capacity and fair evaluation of the advantages. This dynamic feedback process broke the traditional evaluation system by the higher assessment subordinates.

"Medical research and service object is a person, in the process of medical education must strengthen the arts, science, medicine osmosis and multidisciplinary cross fusion, combine the cultivation of medical ethics and medical skill, strengthen the comprehensive quality training. "Higher medical colleges and universities should strengthen the ideological and moral and humanity quality education of medical students, to lay a good foundation for the medical career in the future.

Professional ethics education of medical institutions at all levels and departments as an important part of political thought education work, regularly carry out various kinds of medical ethics training activities, through the theoretical learning awareness, typical tree, behavior, and promote the good atmosphere of consciously perform professional ethics.

Through the regular examination and appraisal of medical staff's profession morality, constraints, and standardize the 
medical staff of professional conduct. Establish a regular inspection file, recording the inspection appraisal results, as applied, the title promotion, promotion, assessment mode, the important basis of various training.

Western medical college attaches great importance to cultivate medical students' ability of doctor-patient communication, and through courses in doctor-patient communication series, cultivate medical students the knowledge and skills of doctor-patient communication. Medical colleges and universities of our country should further strengthen the reform of the education teaching mode, strengthen humanities education, in particular, courses in medical language and doctor-patient communication, gradually narrowing and "medical education" the gap between international standards, realize the arts, the sciences, medical facilities in the true sense, cultivate high quality medical talents.

In clinical medical practice, the resident should strengthen communication ability training in the following link: collecting medical history, physical examination, choose the reasonable auxiliary examination. To introduce to the patient and family to illness have a check and operation signature. Surgical complications and disease change when patients discharged from hospital and after discharge.

Medical institutions by conducting various forms of training activities, such as lectures, view, competition, etc., strengthen the cultivation of medical staff communication, advocating humanistic medical services.

\section{CONCLUSION}

Doctor's professional ethics and interpersonal communication skills to be further improved. Evaluation feedback system for the evaluation of resident professional moral qualities and interpersonal communication skills to be more objective, scientific, effective and has good feasibility. Evaluation feedback system to cultivate and improve the quality of the resident professional ethics and interpersonal communication ability with good effect, suitable for specific situation resident standardization training in our country, has a good application prospect.

\section{REFERENCES}

[1] Bem DJ. Self-perception theory. Advance in Experimental Social Psychology. New York: Academic Press, 1994.

[2] Schwartz RW, donneily MB, Sloan DA, et a1. Assessing senior residents knowledge and performance: an integrated evaluation program. Surg, 1994, 116(4): 634.

[3] Romano C. Conquerinn the fear of feedback [J]. Human Resource Focus, 1994, 71 (3): 327-341.

[4] Burdick WP, Schoffstall J. Observation of emergency medicine residents at the bedside: How often dose it happen? Acad Eerg Med, 1995, 2 (10): 909.

[5] Meuleman JR, Harvard MP. Assessing medical interview performance. Effect of interns' gender and month of train. Arch Intern Med, 1992, 152(8): 1667.

[6] Josephine M Cassie, Judith S, Armburster M Ian Bowmer, et a1. Accreditation of postgraduate medical education in the United States and Canada: a comparison of two systems [J]. Medical Education, 2008 (33), 493-498. 